\title{
RESEARCH
}

Open Access

\section{Typology of organizational innovation components: building blocks to improve access to primary healthcare for vulnerable populations}

Mélanie Ann Smithman', Sarah Descôteaux², Émilie Dionne ${ }^{2}$, Lauralie Richard ${ }^{3}$, Mylaine Breton ${ }^{4}$, Vladimir Khanassov ${ }^{5}$, Jeannie L. Haggerty ${ }^{5^{*}}$ (D) and On behalf of the IMPACT research team

\begin{abstract}
Background: Achieving equity of access to primary healthcare requires organizations to implement innovations tailored to the specific needs and abilities of vulnerable populations. However, designing pro-vulnerable innovations is challenging without knowledge of the range of possible innovations tailored to vulnerable populations' needs. To better support decision-makers, we aimed to develop a typology of pro-vulnerable organizational innovation components - akin to "building blocks" that could be combined in different ways into new complex innovations or added to existing organizational processes to improve access to primary healthcare.

Methods: To develop the typology, we used data from a previously conducted a) scoping review (2000-2014, searched Medline, Embase, CINAHL, citation tracking, $n=90$ articles selected), and b) environmental scan (2014, online survey via social networks, $n=240$ innovations). We conducted a typological analysis of the data. Our initial typology yielded 48 components, classified according to accessibility dimensions from the Patient-Centred Accessibility Framework. The initial typology was then field-tested for relevance and usability by health system stakeholders and refined from 2014 to 2018 (e.g., combined similar components, excluded non-organizational components).

Results: The selected articles ( $n=90$ studies) and survey responses ( $n=240$ innovations) were mostly from the USA, Canada, Australia and the UK. Innovations targeted populations with various vulnerabilities (e.g., low income, chronic illness, Indigenous, homeless, migrants, refugees, ethnic minorities, uninsured, marginalized groups, mental illness, etc.). Our final typology had 18 components of organizational innovations, which principally addressed Availability \& Accommodation (7/18), Approachability (6/18), and Acceptability (3/18). Components included navigation \& information, community health worker, one-stop-shop, case management, group visits, defraying costs, primary healthcare brokerage, etc.

(Continued on next page)
\end{abstract}

\footnotetext{
* Correspondence: jeannie.haggerty@mcgill.ca

${ }^{5}$ Department of Family Medicine, McGill University, Montreal, Quebec, Canada

Full list of author information is available at the end of the article
}

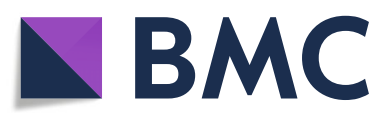

( The Author(s). 2020 Open Access This article is licensed under a Creative Commons Attribution 4.0 International License, which permits use, sharing, adaptation, distribution and reproduction in any medium or format, as long as you give appropriate credit to the original author(s) and the source, provide a link to the Creative Commons licence, and indicate if changes were made. The images or other third party material in this article are included in the article's Creative Commons licence, unless indicated otherwise in a credit line to the material. If material is not included in the article's Creative Commons licence and your intended use is not permitted by statutory regulation or exceeds the permitted use, you will need to obtain permission directly from the copyright holder. To view a copy of this licence, visit http://creativecommons.org/licenses/by/4.0/ The Creative Commons Public Domain Dedication waiver (http://creativecommons.org/publicdomain/zero/1.0/) applies to the data made available in this article, unless otherwise stated in a credit line to the data. 
(Continued from previous page)

Conclusions: This typology offers a comprehensive menu of potential components that can help inform the design of pro-vulnerable organizational innovations. Component classification according to the accessibility dimensions of the Patient-Centred Accessibility Framework is useful to help target access needs. Components can be combined into complex innovations or added to existing organizational processes to meet the access needs of vulnerable populations in specific contexts.

Keywords: Primary healthcare, Vulnerable population, Health services accessibility, Multiple classification analyses, Organizational innovation

\section{Background}

Equity of access to healthcare - and specifically, to primary healthcare - is a core value in public policy and a feature of highly-performing health systems in many high-income countries [1-3]. Although reforms to strengthen primary healthcare often invoke equity as a principal goal, they rarely succeed in adequately reaching vulnerable populations whose needs tend to be more complex than those of the general population [4-9]. Indeed, many innovations to improve access to care tend to favour the wealthiest or most educated segments of the population - as famously captured by the Inverse Care Law [10]. Achieving healthcare equity, therefore, requires organizations to implement pro-vulnerable innovations, tailored to reach and meet vulnerable populations' specific needs [11].

Vulnerable populations are groups or individuals who are more susceptible to harm because they lack the personal, material, and social resources to successfully cope with the challenges they face and to counter potential harm [12]. These populations are at higher risk for poor health status and problematic access to healthcare $[4,13]$. Vulnerable populations include: Aboriginal or Indigenous communities, refugees, visible ethnic minorities, individuals living in poverty, people experiencing homelessness, people with disabilities, people with limited social support, those with complex health conditions, certain age groups; and many other marginalized and underserved populations [4, 13-17]. Inequitable access to healthcare stems from gaps between vulnerable populations' abilities to access care, and healthcare organizations' accessibility (see Fig. 1) [18]. To close these gaps, healthcare organizations must adapt their accessibility to vulnerable populations' abilities. However, designing pro-vulnerable innovations is challenging for decision-makers, providers, and other health system

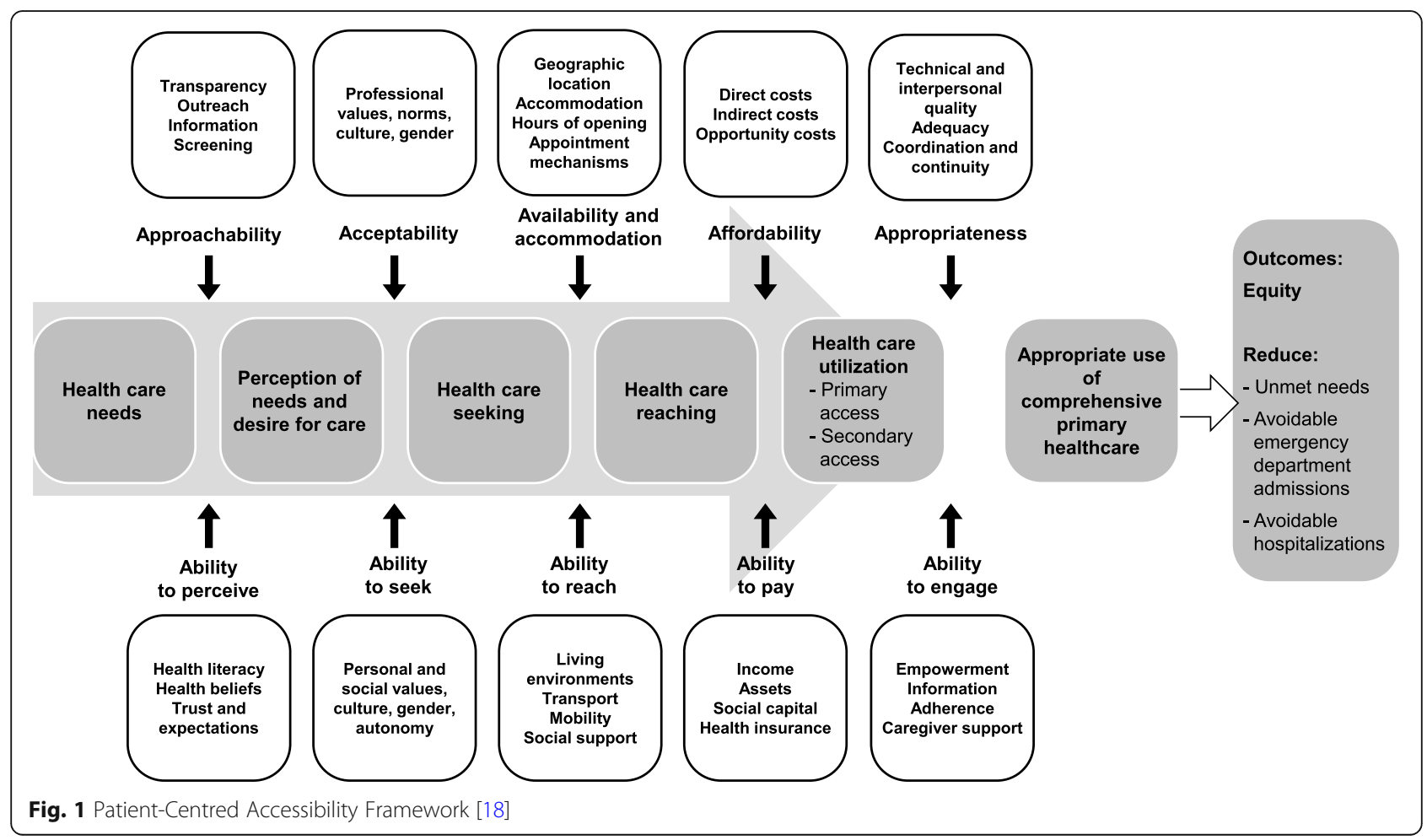


stakeholders, as they may lack knowledge of the range of possible innovations to address vulnerable populations' specific needs.

This challenge of designing pro-vulnerable innovations was highlighted in our "Innovative Models Promoting Access-to-Care Transformation" (IMPACT) research program [19]. IMPACT brought together local health system decision-makers, providers, primary healthcare researchers, community members, and other stakeholders in six regions in Canada and Australia. In each region, a local multi-stakeholder partnership designed and piloted an organizational innovation aiming to improve access to primary healthcare for vulnerable populations. A foundational premise of the IMPACT program was that innovations should aim to adapt primary care organizations and service delivery arrangements to meet vulnerable populations' needs, rather than placing the onus solely on vulnerable populations to improve their abilities to access care. To inspire local health system partners, the research team was to provide a menu of existing pro-vulnerable organizational innovations to improve access to primary care.

Substantial research has been conducted on interventions to improve the delivery of care - most notably the taxonomy produced by the Effective Practice and Organisation of Care (EPOC) Group Cochrane Review Group [20]. However, they provide an overview of general interventions that, for the reasons highlighted above, may not address the specific needs of vulnerable populations. Early in the IMPACT program, members of the team conducted a scoping review of studies that described organizational innovations that improved vulnerable populations' access to primary healthcare - significantly reducing unmet need for care, use of hospital emergency rooms or hospital admissions [17]. This scoping review [17] presented complex interventions, mapped onto the EPOC taxonomy, in which various components of interventions appeared across different interventions. While decision-makers appreciated having results specific to vulnerable populations, they found transposing the results to their contexts challenging and, therefore, of limited use to inform the design of organizational provulnerable innovations.

To better support decision-makers, we aimed to develop a typology of pro-vulnerable organizational innovation components - akin to "building blocks" that could be combined in different ways into new complex innovations or added to existing organizational processes. This typology is intended to provide a comprehensive range of components of organizational innovations to be considered by health service decision-makers as options to address the primary healthcare access needs of vulnerable populations.

\section{Methods \\ Design: typology}

We developed a typology of components of organizational innovations. A typology is a description and categorization of complex organizational forms [21] developed using qualitative (or quantitative) analysis [22]. The goal of a typology is to divide a whole phenomenon - in our case, organizational innovations to improve access to primary healthcare for vulnerable populations - into distinct but related categories [22, 23]. Typologies have been used in primary healthcare with the intent of guiding organizational change and can provide a "menu" of items to inform the design of interventions [24-29]. In a "typology" - as opposed to a "taxonomy" - items are not ordered hierarchically and are not entirely mutually exclusive.

A qualitative typology is generally structured around a conceptual framework that helps classify emerging categories [22, 23]. In the IMPACT research program, access to primary healthcare for vulnerable populations was conceptualized primarily based on the PatientCentred Accessibility Framework [18]. This framework posits that access to healthcare results from the interaction, at different stages, between organizational dimensions of healthcare and patients' abilities (Fig. 1). We focused on the dimensions of accessibility on the organizational side of the framework (i.e., Approachability, Acceptability, Availability \& Accommodation, Affordability, and Appropriateness).

Inspired by Greenhalgh et al. [30], we defined organizational innovations as: "a novel set of organizational behaviours, routines, and ways of working that are directed at [a common objective] and that are implemented by planned and coordinated actions." Organizational innovations to improve access to primary healthcare for vulnerable populations were identified from two complementary sources of data: a) a scoping review of the peer-reviewed literature [17] and b) an environmental scan [16]. Both are described briefly below and have been described in detail elsewhere [16, 17]. The scoping review and scan were conducted as part of the IMPACT research program [19].

\section{Data source: a) scoping review}

A scoping review was conducted to explore the breadth of available evidence on organizational innovations in primary healthcare [17]. The search focused on academic, peer-reviewed literature and was conducted in three of the largest and most relevant databases for studies related to primary healthcare (Medline, Embase, and CINAHL). The search was performed by a specialized librarian (see an example of the search strategy in Additional file 1). In addition to the database searches, four primary care experts from the IMPACT team (including 
$\mathrm{JH})$ were asked to share their personal primary care reference files, from which citation tracking was performed to identify additional relevant studies. The search was limited to articles published between January 2000 and March 2014, a period corresponding to an international commitment to strengthening primary healthcare, up to the beginning of the IMPACT program. One researcher (VK) scanned 8694 titles and abstracts for relevance, then assessed 1760 potentially relevant studies for eligibility. For the typology, we selected any quantitative, qualitative, or mixed methods studies carried out in Organization for Economic Cooperation and Development (OECD) countries and published in English or French that met all four of the following eligibility criteria:

(1) involved at least one organization at the primary healthcare level in the health system;

(2) was organizational (not directed at the system as a whole or only to the population);

(3) had an explicit objective to improve access to care;

(4) was directed to a vulnerable population.

The 129 eligible full texts were read by three team members (MAS, JH, SD) to select 90 articles where innovations were described in detail.

\section{Data source: b) environmental scan}

The environmental scan was conducted after the review. It was designed to capture organizational innovations that had not been published in the academic literature [16]. Briefly, a 5-min online survey was disseminated using a social network approach over 6 weeks between July 10 and August 21, 2014. Primary healthcare informants known to the research team were sent a link to the online survey by email and, in turn, were asked to share the survey link within their social networks. The survey was also promoted on social media through 248 posts on Twitter linked to findings of interest and emerging findings from the survey. Participants were invited to identify a program, service, approach, or model of care that they considered innovative in helping vulnerable populations access primary healthcare. They were encouraged to provide links to any available description, such as websites or documents. The definition of an organizational innovation was left to the discretion of the respondents to ease the response burden. We received 744 survey responses. After screening innovations for eligibility and redundancy, 240 unique innovations were retained for the typology.

\section{Typological analysis}

We conducted a typological analysis [22, 23]: first, a) of the selected peer-reviewed articles $(n=90)$ and, subsequently, b) of the selected survey responses $(n=$ $240)$. Each article $(n=90)$ was carefully read independently by two individuals (MAS, SD), who focused on the 'types' of organizational innovations that addressed accessibility and highlighting all passages describing the innovation. The highlighted passages were used to draft a detailed description of each innovation in an Excel document. For each article, we also extracted information about the setting, target population, and vulnerabilities addressed (e.g., frail elderly, homeless, Aboriginal, low income). Reading the detailed description of each innovation, we used a predominantly inductive approach, grouping similar components recurring across organizational innovations. The unit of analysis was a distinct component that could either be a stand-alone intervention (navigation \& information), or a combination of components consistently occurring together (e.g., case management, advanced access). We applied standard labels to components where possible (e.g., community health worker) and descriptive labels to others (e.g., proactive identification of need, cultural adaptation).

Subsequently, the emerging typology components were tested by coding the survey responses $(n=240)$ from the scan. Two individuals (MAS, LR) independently coded the responses in an Excel document, then met to resolve discrepancies and discuss possible additions and clarifications to the typology components.

Our initial analysis yielded 48 unique innovation components. Most of the innovations reported in the studies were complex interventions that involved 1-14 components, with an average of six components each. Almost all components were established in the first 40 published studies; analysis of additional published studies and the environmental scan led to refinements. The scoping review and scan data coding were reviewed based on this initial typology and adjusted for consistency and to ensure all relevant components had been captured. We then reviewed the innovations coded to each component of the typology to write a short general description of the component and to select illustrative examples of the component.

Two individuals (MAS, JH) then reviewed the initial typology components, descriptions, and examples and mapped them to the organizational dimensions of the Patient-Centred Accessibility Framework [18]. The classifications were based on principal and secondary dimensions of accessibility addressed by the component. Discrepancies in classification were resolved through discussion and checked by the rest of the team.

\section{Typology field-testing and refinement}

The scoping review and environmental scan were conducted in 2014. From 2014 to 2018, the initial typology 
was presented to academic audiences and field-tested with local partners (e.g., decision-makers, patients, health professionals, researchers) to help them design pro-vulnerable organizational innovations to improve access to primary healthcare. When these initial components were presented to local partners and peers at conferences, they affirmed that the initial 48 components were useful for expanding the options to be considered when designing an innovation. However, they also perceived redundancy between components or lack of direct relevance to accessibility. Therefore, we excluded components that were not organizational components per se, but rather resourcing mechanisms: student health professionals, financial incentives, organizational networks, and provider education. We also excluded components that are, in fact, care attributes, such as transparency, advocacy, patient-centred care, and empowerment. Finally, we excluded a few components that applied more to the content or quality of care, such as quality improvement initiatives or self-management education. Components of a similar nature were further collapsed into 18 components of organizational innovations.

\section{Results}

\section{Organizational innovation characteristics}

The 90 selected peer-reviewed studies were set in: the USA $(n=60)$ [31-90], Canada $(n=9)$ [91-99], Australia $(n=8)$ [100-107], UK $(n=6)$ [108-113], New Zealand $(n=2)[114,115]$, Israel $(n=2)[116,117]$, Italy $(n=1)$ [118], Mexico $(n=1)$ [119], and Germany $(n=1)$ [120]. For the environmental scan survey, $45.0 \%$ of responses originated from Canada, 40.8\% from Australia, 9.4\% from others countries (e.g., Ireland, UK, USA, Netherlands, Italy, Israel, Switzerland, Cameroon, India, Indonesia, Sudan) and $4.8 \%$ were missing country information [16].

The organizational innovations identified in our data targeted a wide variety of vulnerable populations. Targeted populations typically combined various vulnerabilities, most commonly: low-income, chronic illnesses, Indigenous populations, homeless, migrant or refugee status, ethnic minorities, uninsured or underinsured, marginalized groups (drug users, recently incarcerated), persons with mental illness, the frail elderly, at risk youth, and frequent users of emergency departments.

\section{Typology}

The final typology was comprised of 18 components of organizational innovations, presented with examples [42-44, 54-61, 78-83, 94-96, 105, 110, 113, 119-136] in Table 1. The innovation components are organized by the principal accessibility dimension they address. The 18 components principally addressed the dimensions of
Availability \& Accommodation (7/18), Approachability (6/18), and Acceptability (3/18). Only one component addressed each of Affordability and Appropriateness as principal dimensions, although these were addressed as secondary dimensions as part of other innovation components.

\section{Discussion}

The integration of the scoping review and environmental scan of innovations along with field-testing resulted in a typology of 18 components of organizational innovations to enhance the accessibility of primary healthcare for vulnerable populations. The typology was based on both published and unpublished innovations. It offers a comprehensive menu of potential components that can help inform the design of innovations and can be combined into complex interventions or added to existing organizational processes to meet the access needs of vulnerable populations. Mapping of the components to the accessibility dimensions of the Patient-Centred Accessibility Framework [18] allows health service designers to match appropriate innovations to identified access needs.

The typology offers a categorization of health service delivery arrangements inspired by the Cochrane taxonomy of EPOC [20], but tailored to the needs of service designers and specific to the domain of access for vulnerable populations. The ultimate goal is to improve healthcare equity through pro-vulnerable innovation design. A few components are similar to those found in the EPOC and are not specific to vulnerable populations, including group visits, expanded hours, advanced access, virtual health services, one-stop-shops, and role expansion. However, they have been demonstrated to be wellsuited to address the needs of specific vulnerable populations, although organizations still have to be intentional about a pro-vulnerable focus to achieve healthcare equity. Other components in the typology are specifically designed to address the needs of vulnerable populations and differ from the EPOC taxonomy. Proactive identification of need, proactive appointment making and contact, and outreach pull vulnerable persons into primary healthcare and maintain contact rather than placing the onus on vulnerable populations to perceive their needs and navigate the care-seeking process. Similarly, community health workers, service brokerage, and transportation services bridge the gap between the health system and vulnerable populations.

Despite the intention to make labels and descriptions as mutually exclusive as possible, there was considerable overlap between some components. For instance, navigation and information and proactive identification of need, although implemented as stand-alone innovations, are also functions of community health workers and case 


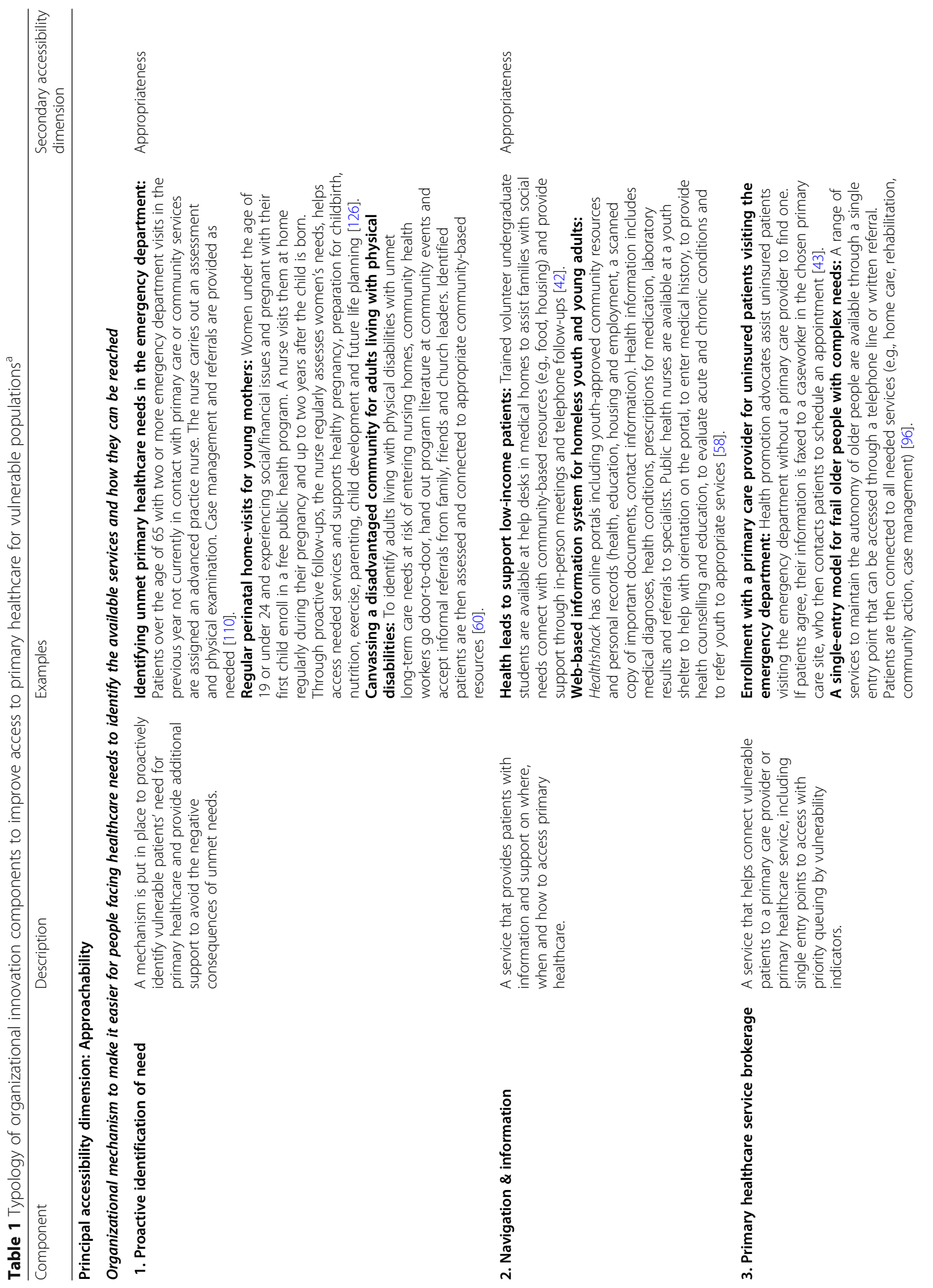




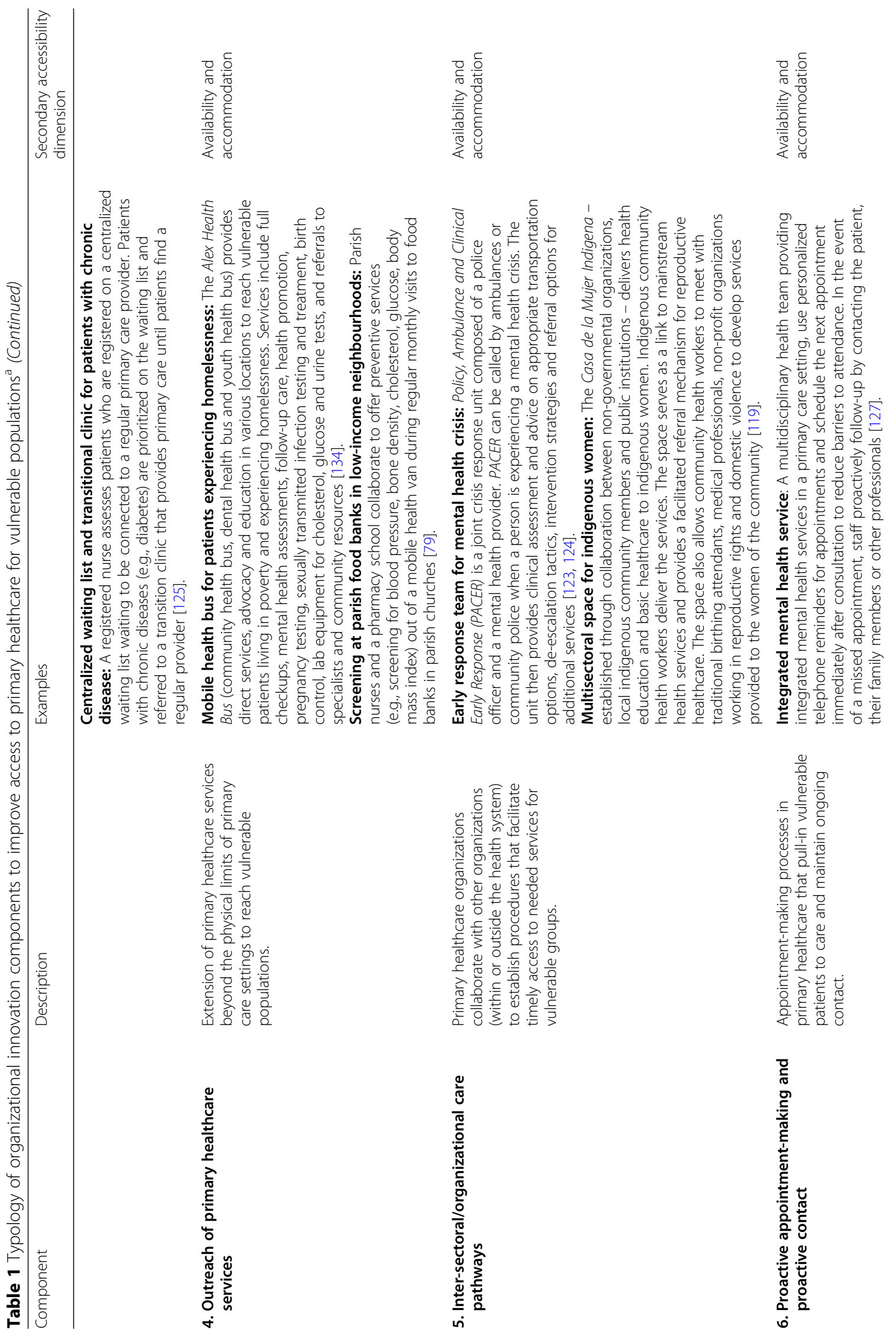



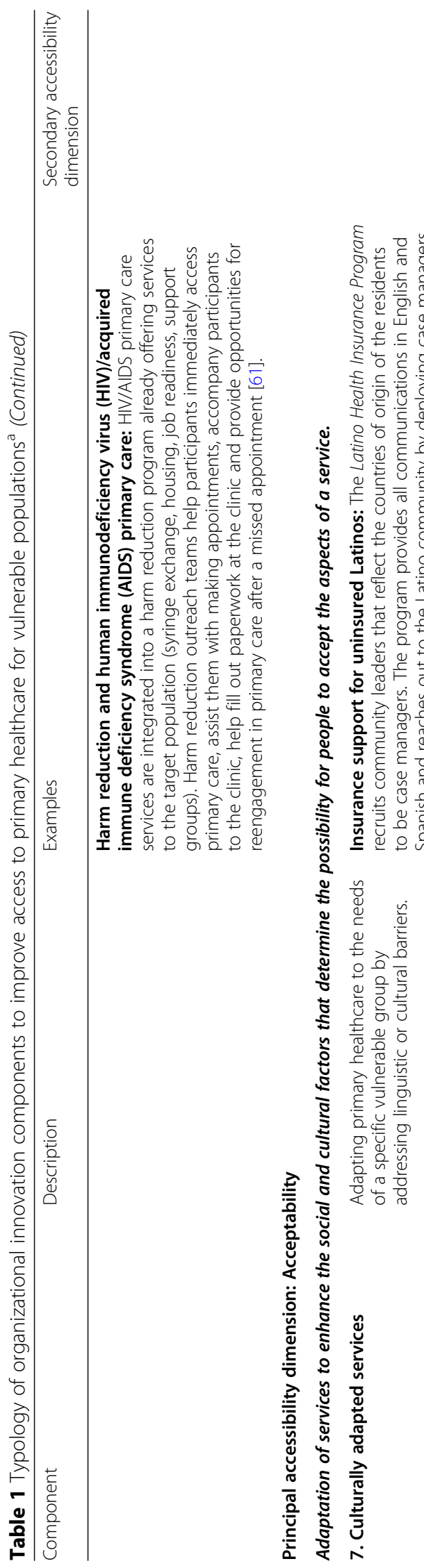

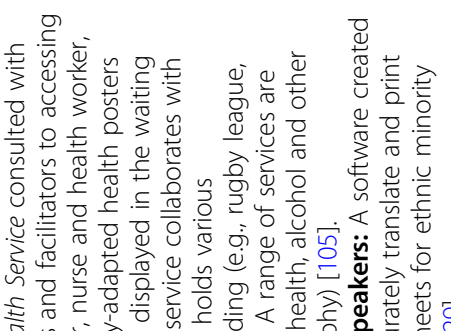

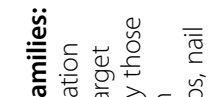

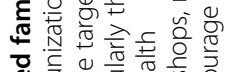

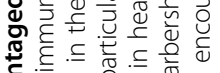

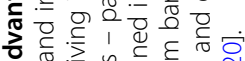

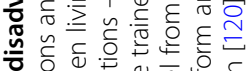

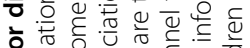

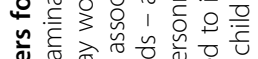

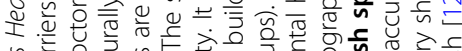

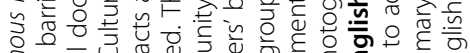

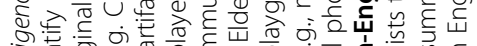

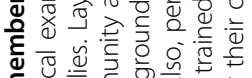

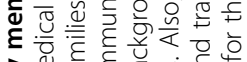

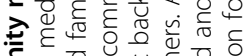

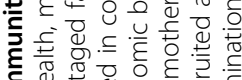

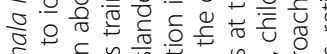

$\frac{2}{2} \frac{\bar{d}}{\underline{U}}$

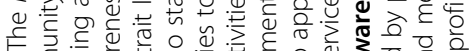

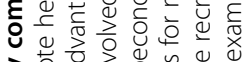

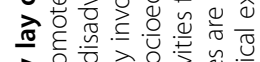

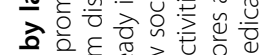

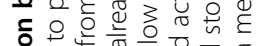
흔,

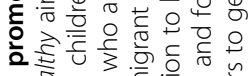

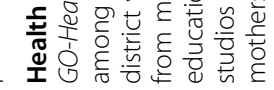

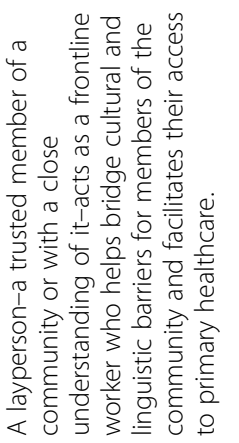



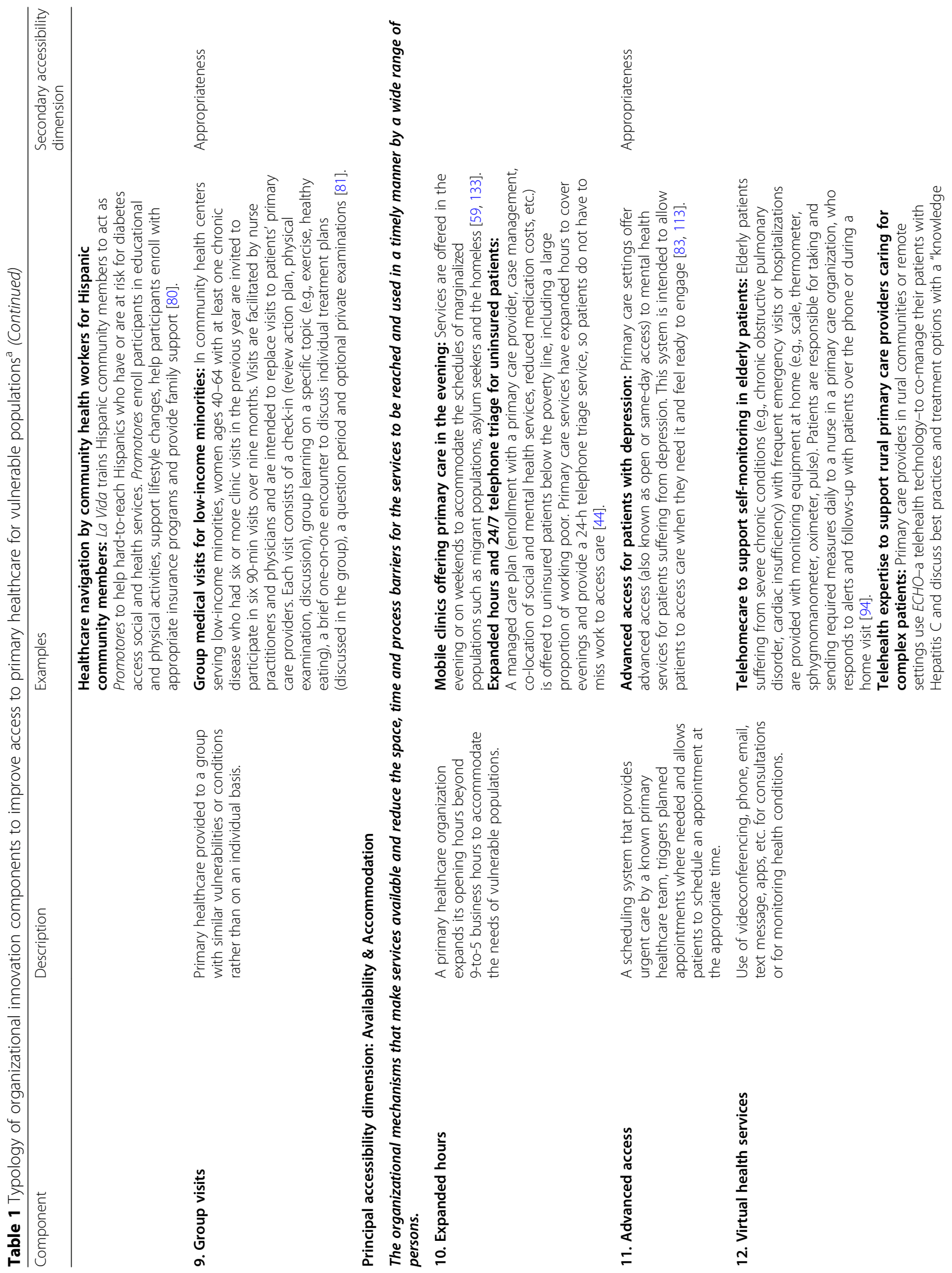


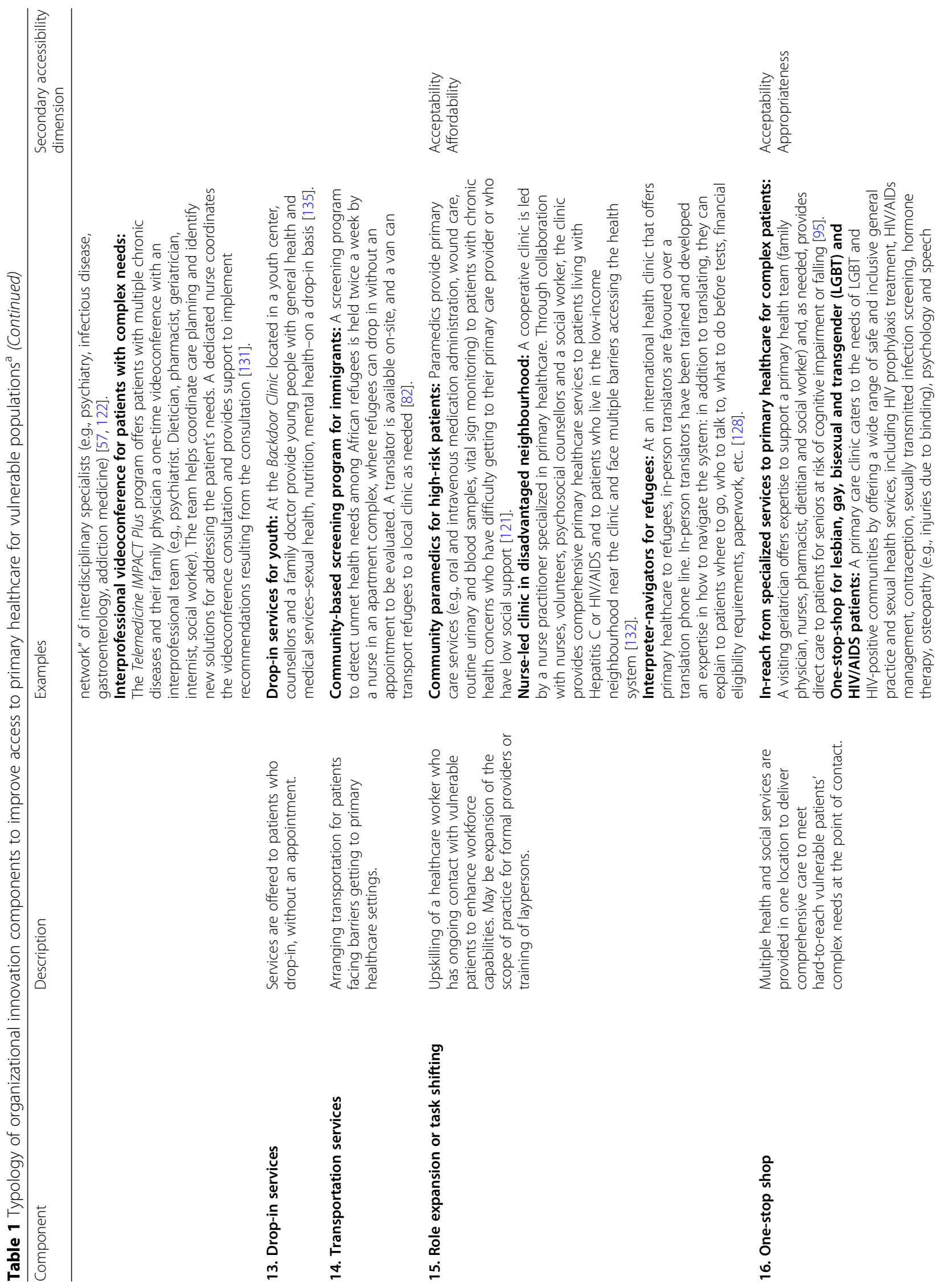



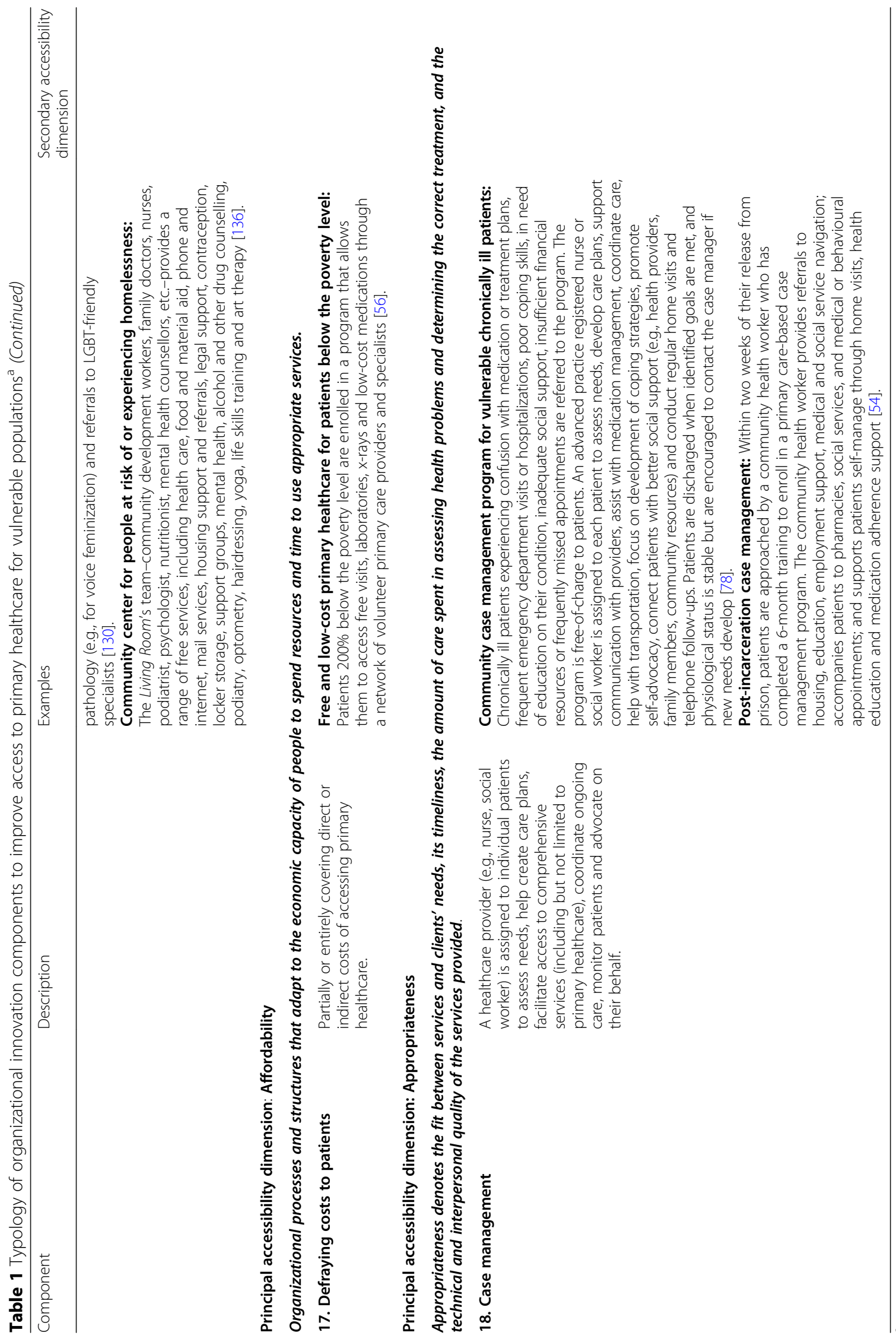

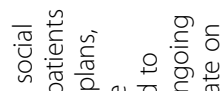

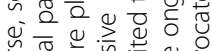

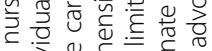

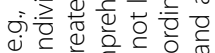

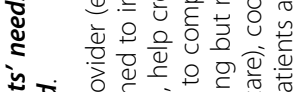

密害

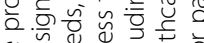

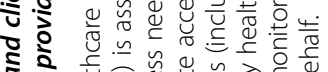

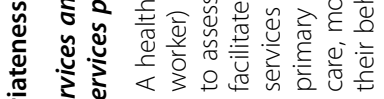


managers. Likewise, culturally adapted services or interorganizational pathways are functions of community health workers or role expansion innovations; these can be implemented as stand-alone interventions or added to existing organizational processes to address an accessibility need.

\section{Using the typology in the design of innovations}

This typology is intended to provide "building blocks" that can be combined into complex innovations or added to existing organizational processes to address specific access needs of vulnerable populations. The analysis done by Khanassov et al. [17] emphasizes that interventions are most effective in reducing unmet needs, emergency department visits, and hospitalizations when the intervention components are formally coordinated or integrated with other parts of the health system. Integration and coordination are critical considerations in implementing any of these interventions.

The Patient-Centered Accessibility Framework [18] is helpful in both identifying the access needs of the population and the components that are most appropriate to address those needs. For example, a population that frequently visits the emergency department may require an innovation that targets Approachability or Acceptability (e.g., navigation \& information, proactive identification of need, culturally adapted services). Conversely, if the target population is seeking services but is disengaged from ongoing care, then Appropriateness-related components such as proactive appointment-making, case management, or one-stop shops may be better suited.

It is not surprising that most of the innovation components pertain to Approachability and Availability \& Accommodation. Several studies have highlighted that vulnerable populations often face difficulties perceiving health needs, navigating the health system to find services, finding time to obtain services, making an appointment, and finding transportation to reach services [18, 137-139]. This typology emphasizes the importance of addressing barriers early in the care-seeking trajectory and provides a range of potential solutions to mitigate these barriers.

Although other components addressed Affordability as a secondary dimension, it is surprising that only one component in the typology (defraying costs to patients) related principally to Affordability, especially given the importance of direct and indirect cost as a barrier to care for vulnerable populations [140-143]. This result is partly due to our focus on identifying organizational innovations that can be implemented by a single organization or sub-system. Macro-level 'innovations,' such as universal health insurance and the Affordable Care Act, were excluded from our analysis because they are country-level legislative policies rather than organizational innovations.

\section{Example of how the typology has been used}

As mentioned, the typology was field-tested for relevance and usability in our local partnerships between 2014 and 2018 as they designed and piloted innovations to address local access priorities for vulnerable populations. In the local partnership in Quebec (Canada), a preliminary version of the typology was used to inform discussions about the design of an innovation for patients from disadvantaged neighbourhoods who face barriers connecting with a regular primary care provider. The innovation was a combination of several components: trained volunteer community members (inspired by community health workers) reached out to patients from disadvantaged neighbourhoods who were on the provincial centralized waiting list to find a primary care provider (existing primary healthcare brokerage) to screen for potential access barriers (proactive identification of need). These volunteers provided support by telephone before and after their first visit with their new primary care provider, including discussing the importance of attending the first visit, offering information about the clinic, giving visit preparation materials, and providing general information about the health system (navigation $\mathcal{E}$ information). Stakeholders in the local partnership perceived the typology as a useful tool to expand the menu of innovations and to reflect on how components could be added to existing organizational processes. Furthermore, we used the typology and the $\mathrm{Pa}$ tient-Centred Access Framework [18] to describe each local partnership's innovations. This tool allowed the IMPACT research team, which spanned six sites in Canada and Australia with different contexts, languages, and terminology, to clarify their aims, improve mutual understanding across sites, and compare their innovations.

\section{Implementing components of an innovation}

The selection of components as part of a complex innovation also depends on the resources and implementation control available to innovation designers. The decision to implement components such as group visits, dropin services, facilitated appointment making, expanded hours, culturally adapted services, case management, or advanced access are generally within the control of a single primary healthcare organization and can be resourced through the reorganization of existing resources. In contrast, components such as outreach of primary healthcare services, transportation, and navigation E information services require investment of new resources that may be possible for a single organization with a strong commitment and sufficient resources. Other components, such as role expansion and virtual health services, may require changes at a higher level since they involve changes 
beyond the reach of a single organization. For instance, role expansion - such as nurses working at the top of their scope of practice or empowering front office staff to refer patients to social workers - may require collaboration with professional associations to modify regulations governing professional practice. Similarly, implementing a community health worker may require collaboration with other organizations to set up certified training programs or to secure funding to cover salaries. Similarly, one-stop shops or inter-organizational pathways are based on collaborations between various organizations outside of primary healthcare and require substantial support and political will from local or regional health authorities for implementation.

\section{Strengths and limitations}

Because we achieved saturation with the peer-reviewed articles from the scoping review and descriptions of innovations from the environmental scan, we are reasonably confident that this typology reflects the most common innovation components to improve access for vulnerable populations. We recognize that we have excluded innovations outside the study period. Yet, as 2000 to 2014 represents a period of renewal and reform for primary healthcare marked by an effervescence of innovations, we believe that we have captured the most common components to improve access to primary care. Since 2014, we have continued to test the comprehensiveness of our typology by informally comparing it to innovations described in more recent peer-reviewed studies (although we did not use the systematic approach applied to the literature of the study period). In subsequent presentations to international audiences at conferences, we heard of additional examples of innovations, such as organizational arrangements between hospitals and farmers' markets, but were able to locate them within typology components. We have not found any new components emerging from more recent literature or examples of innovations to add to our typology. An additional strength of this study is that from 2014 to 2018, the typology was field-tested for usability and relevance with local partners to design pro-vulnerable innovations. We are therefore reasonably confident that, although a new scan or scoping review would add detail and examples to the typology, it would not fundamentally change the components.

We also recognize that our scoping review data, from which we developed our initial typology components, described innovations in only nine OECD countries (Canada, USA, UK, Australia, Germany, New Zealand, Italy, Israel, and Mexico). We minimized the effect of publication bias by doing an environmental scan to identify unpublished innovations, but this method is susceptible to selection bias. Most responses came from Australia and Canada, and running the survey during the Northern Hemisphere's summer may have limited responses from Europe and the USA. We also have no way of assessing the response rate or comprehensiveness of responses gathered using the social media approach. Although we did have a small number of respondents from low-income countries in our environmental scan, our approach may have excluded some innovative initiatives in low- and middle-income countries (e.g., community-based insurance plans [144], identification of accredited clinics [145], and subsidized payments for primary healthcare services [146]. Another example is the well-known hub-and-spoke models in India [147], which combine role expansion with inter-organizational pathways to provide low-cost, high-quality services to underserved populations [148].

A final limitation is that the typology labels reflect available examples and the judgment and language of the analysts. Labels such as proactive identification of need are clumsy but they circumscribe a unique set of examples.

\section{Conclusions}

This typology is unique as it presents components of innovations that can be put in place by primary healthcare organizations or other health system stakeholders to improve access to primary healthcare for vulnerable populations. Further research on the effectiveness of combining different components may help inform efforts to improve access for vulnerable populations.

\section{Supplementary information}

Supplementary information accompanies this paper at https://doi.org/10. 1186/s12939-020-01263-8.

Additional file 1. Example of Search Strategy for Embase.

\section{Abbreviations}

EPOC: Effective Practice and Organization of Care; IMPACT: Innovative Models Promoting Access-to-Care Transformation; OECD: Organization for Economic Cooperation and Development

\section{Acknowledgements}

In addition to the authors listed, the IMPACT study acknowledges the commitment provided by the entire research team and stakeholders in local partnerships in Canada and Australia. A special thanks to Pierre Pluye, who co-designed the scoping review with Vladimir Khanassov and to Jane Gunn, who co-designed the environmental scan with Lauralie Richard. JeanFrédéric Levesque, Grant Russell, Virginia Lewis, and Cathie Scott facilitated workshops with different audiences to test the relevance and salience of the initial typology. Lisa Starr helped with editing the manuscript and with references.

\section{Authors' contributions}

Data for the typology were planned and collected by VK (scoping review) and LR (environmental scan). VK assessed the eligibility criteria for potentially relevant studies. JH, MAS, and SD selected eligible studies from the database of studies screened for the scoping review. MAS extracted data and coded all selected studies in the scoping review and all survey entries from the environmental scan. JH and MAS led the inductive analysis to identify emerging components and further refine the typology. SD proposed a set of reduced categories. MB reviewed French survey responses at a preliminary stage of the environmental scan and participated in the application of the typology to health system decision-makers. $\mathrm{JH}$ and MAS drafted the 
manuscript, and ED contributed. All authors read and approved the final manuscript.

\section{Funding}

This project was part of the IMPACT research program, funded by Canadian Institutes of Health Research (TTF-130729) Signature Initiative in CommunityBased Primary Healthcare, the Fonds de recherche Québec - Santé, and the Australian Primary Healthcare Research Institute, which was supported by a grant from the Australian Government Department of Health under the Primary Healthcare Research, Evaluation and Development Strategy. The information and opinions contained in this paper do not necessarily reflect the views or policy of these funding agencies or the Australian Government Department of Health.

\section{Availability of data and materials}

The datasets used and/or analyzed during the current study are available from the corresponding author on reasonable request.

\section{Ethics approval and consent to participate}

The environmental scan received full ethics approval from the University of Melbourne Human Research Ethics Committee (1442125.1). Participation in the survey was voluntary, and consent was obtained by respondents filling out and submitting their survey.

\section{Consent for publication}

Not applicable.

\section{Competing interests}

The authors declare that they have no competing interests.

\section{Author details}

${ }^{1}$ Centre de recherche Charles-Le Moyne - Saguenay-Lac-Saint-Jean sur les innovations en santé, Université de Sherbrooke, Longueuil, Québec, Canada. ${ }^{2}$ St. Mary's Research Centre, McGill University, Montreal, Quebec, Canada. ${ }^{3}$ Department of General Practice and Rural Health, Dunedin School of Medicine, University of Otago, Dunedin, New Zealand. ${ }^{4}$ Department of Community Health, Université de Sherbrooke, Longueuil, Quebec, Canada. ${ }^{5}$ Department of Family Medicine, McGill University, Montreal, Quebec, Canada.

Received: 19 March 2020 Accepted: 19 August 2020

Published online: 06 October 2020

\section{References}

1. World Health Organization. Declaration of Alma-Ata. International Conference on Primary Health Care. Alma-Ata, USSR; 1978.

2. World Health Organization. Primary care, now more than ever. Geneva: World Health Organization; 2008.

3. World Health Organization. Health systems financing: the path to universal coverage. Geneva: World Health Organization; 2010.

4. Harris MF, Harris E, Roland M. Access to primary health care: three challenges to equity. Aust J Prim Health. 2004;10(3):21-9.

5. Bowen S. Access to health services for underserved populations in Canada. In: Health Canada. "Certain circumstances": issues in equity and responsiveness in access to health care in Canada. Ottawa: Health Canada; 2001. p. 1-60

6. Spike EA, Smith MM, Harris MF. Access to primary health care services by community-based asylum seekers. Med J Aust. 2011;195(4):188-91.

7. Khandor E, Mason K, Chambers C, Rossiter K, Cowan L, Hwang SW. Access to primary health care among homeless adults in Toronto, Canada: results from the street health survey. Open Med. 2011;5(2):e94-e103.

8. Hutchison B, Levesque J, Strumpf E, Coyle N. Primary health care in Canada: systems in motion. Milbank Q. 2011;89(2):256-88.

9. Bennett CC. A healthier future for all Australians: an overview of the final report of the National Health and hospitals reform commission. Med J Aust. 2009;191(7):383-7.

10. Hart JT. The inverse care law. Lancet. 1971;297(7696):405-12.

11. Haggerty J, Chin MH, Katz A, Young K, Foley J, Groulx A, et al. Proactive strategies to address health equity and disparities: recommendations from a bi-national symposium. J Am Board Fam Med. 2018;31(3):479-83.
12. Mechanic D, Tanner J. Vulnerable people, groups, and populations: societal view. Health Aff. 2007;26(5):1220-30.

13. Shi L, Stevens GD. Vulnerability and unmet health care needs. The influence of multiple risk factors. J Gen Intern Med. 2005;20(2):148-54.

14. Meyer SB, Luong TC, Mamerow L, Ward PR. Inequities in access to healthcare: analysis of national survey data across six Asia-Pacific countries. BMC Health Serv Res. 2013;13:238.

15. Comino EJ, Davies GP, Krastev Y, Haas M, Christl B, Furler J, et al. A systematic review of interventions to enhance access to best practice primary health care for chronic disease management, prevention and episodic care. BMC Health Serv Res. 2012;12:415.

16. Richard L, Furler J, Densley K, Haggerty J, Russell G, Levesque J-F, et al. Equity of access to primary healthcare for vulnerable populations: the IMPA CT international online survey of innovations. Int J Equity Health. 2016;15:64

17. Khanassov V, Pluye P, Descoteaux S, Haggerty JL, Russell G, Gunn J, et al. Organizational interventions improving access to community-based primary health care for vulnerable populations: a scoping review. Int J Equity Health. 2016;15:168

18. Levesque J-F, Harris MF, Russell G. Patient-centred access to health care: conceptualising access at the interface of health systems and populations. Int J Equity Health. 2013:12:18.

19. Russell G, Kunin M, Harris M, Levesque J-F, Descôteaux S, Scott C, et al. Improving access to primary healthcare for vulnerable populations in Australia and Canada: protocol for a mixed-method evaluation of six complex interventions. BMJ Open. 2019;9(7):e027869.

20. Effective Practice and Organisation of Care Cochrane Review Group. EPOC Taxonomy. 2015. https://epoc.cochrane.org/epoc-taxonomy.

21. Doty $\mathrm{DH}$, Glick WH. Typologies as a unique form of theory building: toward improved understanding and modeling. Acad Manag Rev. 1994;19(2):230-51.

22. Ayres L, Knaft KA. Typological analysis. In: Given LM, editor. The SAGE encyclopedia of qualitative research methods. Volumes $1 \& 2$. Thousand Oaks: SAGE; 2008. p. 900-1.

23. Hatch J. Typological analysis. Doing qualitative research in education settings. Aelbany: State University of New York Press; 2002. p. 152-61.

24. Glenton C, Scheel IB, Lewin S, Swingler GH. Can lay health workers increase the uptake of childhood immunisation? Systematic review and typology. Tropical Med Int Health. 2011;16(9):1044-53.

25. D'Amour D, Goulet L, Labadie J-F, San Martín-Rodriguez L, Pineault R. A model and typology of collaboration between professionals in healthcare organizations. BMC Health Serv Res. 2008;8:1-14.

26. Taggart J, Williams A, Dennis S, Newall A, Shortus T, Zwar N, et al. A systematic review of interventions in primary care to improve health literacy for chronic disease behavioral risk factors. BMC Fam Pract. 2012;13:49.

27. Wakerman J, Humphreys JS, Wells R, Kuipers P, Entwistle P, Jones J. Primary health care delivery models in rural and remote Australia-a systematic review. BMC Health Serv Res. 2008;8:276.

28. Davis LL. Dementia caregiving studies: a typology for family interventions. J Fam Nurs. 1996;2(1):30-55.

29. Preston $\mathrm{R}$, Waugh H, Larkins S, Taylor J. Community participation in rural primary health care: intervention or approach? Aust J Prim Health. 2010; 16(1):4-16.

30. Greenhalgh T, Robert G, Macfarlane F, Bate P, Kyriakidou O. Diffusion of innovations in service organizations: systematic review and recommendations. Milbank Q. 2004;82(4):581-629.

31. Bradley CJ, Gandhi SO, Neumark D, Garland S, Retchin SM. Lessons for coverage expansion: a Virginia primary care program for the uninsured reduced utilization and cut costs. Health Aff. 2012;31(2):350-9.

32. Brown $\mathrm{K}$, Levine J, Fiellin D, O'Connor P, Sledge W. Primary intensive care: pilot study of a primary care-based intervention for high-utilizing patients. Dis Manag. 2005;8(3):169-77.

33. Callahan CM, Boustani MA, Unverzagt FW, Austrom MG, Damush TM, Perkins AJ, et al. Effectiveness of collaborative care for older adults with Alzheimer disease in primary care: a randomized controlled trial. JAMA. 2012;295(18):2148-57.

34. Counsell SR, Callahan CM, Clark DO, Tu W, Buttar AB, Stump TE, et al. Geriatric care management for low-income seniors. A randomized controlled trial. JAMA. 2007;298(22):2623-33.

35. DeHaven M, Kitzman-Ulrich H, Gimpel N, Culica D, O'Neil L, Marcee A, et al. The effects of a community-based partnership, project access Dallas (PAD), on emergency department utilization and costs among the uninsured. J Public Health. 2012;34(4):577-83. 
36. Dorr DA, Wilcox AB, Brunker CP, Burdon RE, Donnelly SM. The effect of technology-supported, multidisease care management on the mortality and hospitalization of seniors. J Am Geriatr Soc. 2008;56(12):2195-202.

37. Driscoll DL, Hiratsuka V, Johnston JM, Norman S, Reilly KM, Shaw J, et al. Process and outcomes of patient-centered medical care with Alaska native people at Southcentral Foundation. Ann Fam Med. 2013;11(Suppl 1):S41-9.

38. Druss BG, Rohrbaugh RM, Levinson CM, Rosenheck RA. Integrated medical care for patients with serious psychiatric illness. JAMA. 2001;58:861-8.

39. Farmer JE, Clark MJ, Sherman A, Marien WE, Selva TJ. Comprehensive primary care for children with special health care needs in rural areas. Pediatrics. 2005;116(3):649-56.

40. Feinglass J, Nonzee NJ, Murphy KR, Endress R, Simon MA. Access to care outcomes: a telephone interview study of a suburban safety net program for the uninsured. J Community Health. 2014;39(1):108-17.

41. Glendenning-Napoli A, Dowling B, Pulvino J, Baillargeon G, Raimer BG. Community-based case management for uninsured patients with chronic diseases: effects on acute care utilization and costs. Prof Case Manag. 2012; 17(6):267-75.

42. Garg A, Marino M, Vikani AR, Solomon BS. Addressing families' unmet social needs within pediatric primary care: the health leads model. Clin Pediatr. 2012;51(12):1191-3.

43. Horwitz SM, Busch SH, Balestracci KMB, Ellingson KD, Rawlings J. Intensive intervention improves primary care follow-up for uninsured emergency department patients. Acad Emerg Med. 2005;12(7):647-52.

44. Kaufman A, Derksen D, McKernan S, Galbraith P, Sava S, Wills J, et al. Managed care for uninsured patients at an academic health center: a case study. Acad Med. 2000;75(4):323-30.

45. Leff B, Reider L, Frick KD, Scharfstein DO, Boyd CM, Frey K, et al. Guided care and the cost of complex healthcare: a preliminary report. Am J Manag Care. 2009:15(8):555-60.

46. Levkoff SE, Chen H, Coakley E, McDonel Herr EC, Oslin DW, Katz I, et al. Design and sample characteristics of the PRISM-E multisite randomized trial to improve behavioral health care for the elderly. J Aging Health. 2004;16(1):3-27.

47. Mackinney T, Visotcky AM, Tarima S, Whittle J. Does providing care for uninsured patients decrease emergency room visits and hospitalizations? J Prim Care Community Health. 2013;4(2):135-42.

48. McCulloch DK, Price MJ, Hindmarsh M, Wagner EH. Improvement in diabetes care using an integrated population-based approach in a primary care setting. Dis Manag. 2000;3(2):75-82.

49. Michelen W, Martinez J, Lee A, Wheeler DP. Reducing frequent flyer emergency department visits. J Health Care Poor Underserved. 2006;17(1 Suppl):59-69.

50. Palfrey JS, Sofis LA, Davidson EJ, Liu J, Freeman L, Ganz ML, et al. The pediatric alliance for coordinated care: evaluation of a medical home model. Pediatrics. 2004;113(5 Suppl):1507-16.

51. Roby DH, Pourat N, Pirritano MJ, Vrungos SM, Dajee H, Castillo D, et al Impact of patient-centered medical home assignment on emergency room visits among uninsured patients in a county health system. Med Care Res Rev. 2010;67(4):412-30

52. Shah R, Chen C, Rourke SO, Lee M, Mohanty SA, Abraham J. Evaluation of care management for the uninsured. Med Care. 2011;49(2):166-71.

53. Wohl DA, Scheyett A, Golin CE, White B, Matuszewski J, Bowling M, et al. Intensive case management before and after prison release is no more effective than comprehensive pre-release discharge planning in linking HIVinfected prisoners to care: a randomized trial. AIDS Behav. 2011;15(2):356-64.

54. Wang EA, Hong CS, Shavit S, Sanders R, Kessell E, Kushel MB. Engaging individuals recently released from prison into primary care: a randomized trial. Am J Public Health. 2012;102(9):e22-9.

55. Abreu M, Hynes HP. The Latino health insurance program: a pilot intervention for enrolling Latino families in health insurance programs, East Boston, Massachusetts, 2006-2007. Prev Chronic Dis. 2009;6(4):A129.

56. Alexander L, Landis S. Low-income uninsured patient health and access to health care through a community health program in NC. J Community Health. 2012;37(1):105-12.

57. Arora S, Kalishman S, Thornton K, Dion D, Murata G, Deming P, et al. Expanding access to hepatitis $C$ virus treatment--extension for community healthcare outcomes $(\mathrm{ECHO})$ project: disruptive innovation in specialty care. Hepatology. 2010;52(3):1124-33.

58. Dang MT, Whitney KD, Virata MCD, Binger MM, Miller E. A web-based personal health information system for homeless youth and young adults. Public Health Nurs. 2011;29(4):313-9.
59. Connor A, Layne L, Thomisee K. Providing care for migrant farm worker families in their unique sociocultural context and environment. J Transcult Nurs. 2010;21(2):159-66.

60. Felix HC, Mays GP, Stewart MK, Cottoms N, Olson M. The care span: Medicaid savings resulted when community health workers matched those with needs to home and community care. Health Aff. 2011;30(7):1366-74.

61. Heller D, McCoy K, Cunningham C. An invisible barrier to integrating HIV primary care with harm reduction services: philosophical clashes between the harm reduction and medical models. Public Health Rep. 2004;119(1):32-9.

62. Brown LD, Stevens B. Charge of the right brigade? Communities, coverage, and care for the uninsured. Health Aff. 2006;25(3):w150-61.

63. Brown LD. Impermanent politics: the Hillsborough County health care plan and community innovation for the uninsured. Health Aff. 2006; 25(3):w162-72.

64. De Leon SF, Pauls L, Shih SC, Cannell T, Wang JJ. Early assessment of health care utilization among a workforce population with access to primary care practices with electronic health records. J Ambul Care Manage. 2013;36(3): 260-8.

65. Desai NR, Smith KL, Boal J. The positive financial contribution of homebased primary care programs: the case of the Mount Sinai visiting doctors. J Am Geriatr Soc. 2008;56(4):744-9.

66. Devoe JE, Gold R, Spofford M, Chauvie S, Muench J, Turner A, et al. Developing a network of community health centers with a common electronic health record: description of the safety net west practice-based research network (SNW-PBRN). J Am Board Fam Med. 2011;24(5):597-604.

67. Diamant $A L$, Brook RH, Fink A, Gelberg L. Assessing use of primary health care services by very low-income adults in a managed care program. Arch Intern Med. 2001;161(9):1222-7.

68. Diaz-Perez MDJ, Farley T, Cabanis CM. A program to improve access to health care among Mexican immigrants in rural Colorado. J Rural Health. 2004:20(3):258-64

69. Dow AW, Bohannon A, Garland S, Mazmanian PE, Retchin SM. The effects of expanding primary care access for the uninsured: implications for the health care workforce under health reform. Acad Med. 2013;88(12):1855-61.

70. Dulin MF, Ludden TM, Tapp H, Smith HA, de Hernandez BU, Blackwell J, et al. Geographic information systems (GIS) demonstrating primary care needs for a transitioning hispanic community. J Am Board Fam Med. 2010; 23(1):109-20.

71. Cady R, Kelly A, Finkelstein S. Home telehealth for children with special health-care needs. J Telemed Telecare. 2008;14(4):173-7.

72. Hamilton LJ, Lerner CF, Presson AP, Klitzner TS. Effects of a medical home program for children with special health care needs on parental perceptions of care in an ethnically diverse patient population. Matern Child Health J. 2013;17(3):463-9.

73. Carey $M$. The role of a statewide information and referral (I\&R) system in enhancing the access of children and their families to developmental programs and services. J Dev Behav Pediatr. 2006;27(1 Suppl):S13-6.

74. Kahn LS, Aiello J, Berdine DE, Fox $\mathrm{CH}$. The use of telephonic case management to link a special-needs population with a primary care physician. J Am Board Fam Med. 2009;22(5):585-7.

75. Kane RL, Homyak P, Bershadsky B, Lum Y-S. Consumer responses to the Wisconsin partnership program for elderly persons: a variation on the PACE model. J Gerontol A Biol Sci Med Sci. 2002;57(4):M250-8.

76. McCann E. Building a community-academic partnership to improve health outcomes in an underserved community. Public Health Nurs. 2010;27(1):32-40.

77. Malvey D, Hyde JC, Topping S, Woodrell FD. Getting off the bandwagon an academic health center takes a different strategic path. J Healthc Manag. 2000:45(6):381-93.

78. Luzinski CH, Stockbridge E, Craighead J, Bayliss D, Schmidt M, Seideman J. The community case management program: for 12 years, caring at its best. Geriatr Nurs. 2008:29(3):207-15.

79. Mayernik D, Resick LK, Skomo ML, Mandock K. Parish nurse-initiated interdisciplinary mobile health care delivery project. J Obstet Gynecol Neonatal Nurs. 2010;39(2):227-334.

80. McCloskey J. Promotores as partners in a community-based diabetes intervention program targeting Hispanics. Fam Community Health. 2009; 32(1):48-57.

81. Miller D, Zantop V, Hammer H, Faust S, Grumbach K. Group medical visits for low-income women with chronic disease: a feasibility study. J Women's Health. 2004;13(2):217-25. 
82. Venters H, Adekugbe O, Massaquoi J, Nadeau C, Saul J, Gany F. Mental health concerns among African immigrants. J Immigr Minor Health. 2011; 13(4):795-7.

83. Watts BV, Shiner B, Pomerantz A, Stender P, Weeks WB. Outcomes of a quality improvement project integrating mental health into primary care. Qual Saf Health Care. 2007;16(5):378-81.

84. Randolph F, Blasinsky M, Morrissey JP, Rosenheck RA, Cocozza J, Goldman $\mathrm{HH}$. Overview of the ACCESS program. Access to community care and effective services and supports. Psychiatr Serv. 2002;53(8):945-8.

85. Reavy K, Hobbs J, Hereford M, Crosby K. A new clinic model for refugee health care: adaptation of cultural safety. Rural Remote Health. 2012;12:1826.

86. Savage RM, Dillon JM, Hammel JC, Lewis TC, Johnson NC, Barlow LM, et al. The Alabama Coalition for a Healthier Black belt: a proof of concept project. Community Ment Health J. 2013;49(1):79-85.

87. Scotten ESL, Absher AC. Creating community-based access to primary healthcare for the uninsured through strategic alliances and restructuring local health department programs. J Public Health Manag Pract. 2006;12(5): 446-51

88. Padwa H, Urada D, Antonini VP, Ober A, Crèvecoeur-MacPhail DA, Rawson RA. Integrating substance use disorder services with primary care: the experience in California. J Psychoactive Drugs. 2012:44(4):299-306.

89. Wang I, Dopheide JA, Gregerson P. Role of a psychiatric pharmacist in a Los Angeles "skid-row" safety-net clinic. J Urban Health. 2011;88(4):718-23.

90. Hockman EM, Andersen M, Smereck GAD. The impact of an intervention program for HIV-positive women on well-being, substance use, physical symptoms, and depression. Drugs Soc. 2001;16(1-2):145-61.

91. Beland F, Bergman H, Lebel P, Clarfield AM, Tousignant P, Contandriopoulos A-P, et al. A system of integrated care for older persons with disabilities in Canada: results from a randomized controlled trial. J Gerontol A Biol Sci Med Sci. 2006:61(4):367-73.

92. Crustolo AM, Kates N, Ackerman S, Schamehorn S. Integrating nutrition services into primary care: experience in Hamilton. Ont Can Fam Physician. 2005;51(12):1647-53.

93. Doey T, Hines P, Myslik B, Leavey JE, Seabrook JA. Creating primary care access for mental health care clients in a community mental health setting. Can J Community Ment Health. 2008:27(2):129-38.

94. Lamothe L, Fortin J-P, Labbé F, Gagnon M-P, Messikh D. Impacts of telehomecare on patients, providers, and organizations. TTelemed J E Health. 2006;12(3):363-9.

95. Moore A, Patterson C, White J, House ST, Riva JJ, Nair K, et al. Interprofessional and integrated care of the elderly in a family health team Can Fam Physician. 2012;58(8):436-41.

96. Tourigny A, Durand PJ, Bonin L, Hébert R, Rochette L. Quasi-experimental study of the effectiveness of an integrated service delivery network for the frail elderly. Can J Aging. 2004;23(3):231-46.

97. Davachi S, Ferrari I. Homelessness and diabetes: reducing disparities in diabetes care through innovations and partnerships. Can J Diabetes. 2012; $36(2): 75-82$

98. Sin DD, Bell NR, Man SFP. Effects of increased primary care access on process of care and health outcomes among patients with asthma who frequent emergency departments. Am J Med. 2004;117(7):479-83.

99. Nardi D. Integrated physical and mental health care at a nurse-managed clinic. J Psychosoc Nurs Ment Health Serv. 2011;49(7):28-34

100. McDermott R, Tulip F, Schmidt B, Sinha A. Sustaining better diabetes care in remote indigenous Australian communities. BMJ. 2003;327(7412):428-30.

101. Anikeeva $O$. The closing the gap initiative - sucesses and ongoing challenges for divisions of general practice. Aust Fam Physician. 2012;41(7):523-7.

102. Carey TA. A qualitative study of a social and emotional well-being service for a remote indigenous Australian community: implications for access, effectiveness, and sustainability. BMC Health Serv Res. 2013;13:80.

103. Gould G, Viney K, Greenwood M, Kramer J, Corben P. A multidisciplinary primary healthcare clinic for newly arrived humanitarian entrants in regional NSW: model of service delivery and summary of preliminary findings. Aust N Z J Public Health. 2010;34(3):326-9.

104. Happell B, Platania-Phung C, Scott D. Mental health nurse incentive program: facilitating physical health care for people with mental illness? Int J Ment Health Nurs. 2013;22(5):399-408.

105. Hayman NE, White NE, Spurling GK. Improving indigenous patients' access to mainstream services: the Inala experience. Med J Aust. 2009;190(10):604-6.

106. Kay M, Jackson C, Nicholson C. Refugee health: a new model for delivering primary health care. Aust J Prim Health. 2010;16(1):98-103.
107. Laurence C, Gialamas A, Yelland L, Bubner T, Ryan P, Willson K, et al. A pragmatic cluster randomised controlled trial to evaluate the safety, clinical effectiveness, cost effectiveness and satisfaction with point of care testing in a general practice setting - rationale, design and baseline characteristics. Trials. 2008;9:50.

108. Carver H, Douglas MJ, Tomlinson JEM. The outreach worker role in an anticipatory care programme: a valuable resource for linking and supporting. Public Health. 2012;126(Suppl 1):S47-52.

109. Day C, Davis H. The effectiveness and quality of routine child and adolescent mental health care outreach clinics. Br J Clin Psychol. 2006;45(Pt 4):439-52.

110. Gravelle H, Dusheiko M, Sheaff R, Sargent P, Boaden R, Pickard S, et al. Impact of case management (Evercare) on frail elderly patients: controlled before and after analysis of quantitative outcome data. BMJ. 2007;334(7583):31.

111. Le Feuvre P. How primary care services can incorporate refugee health care. Med Confl Surviv. 2001;17(2):131-6.

112. Sylvia ML, Griswold M, Dunbar L, Boyd CM, Park M, Boult C. Guided care: cost and utilization outcomes in a pilot study. Dis Manag. 2008;11(1):29-36.

113. Symons L, Tylee A, Mann A, Jones R, Plummer S, Walker M, et al. Improving access to depression care: descriptive report of a multidisciplinary primary care pilot service. Br J Gen Pract. 2004;54(506):679-83.

114. Gray S, Lennon D, Anderson P, Stewart J, Farrell E. Nurse-led school-based clinics for skin infections and rheumatic fever prevention: results from a pilot study in South Auckland. N Z Med J. 2013;126(1373):53-61.

115. Maniapoto T, Gribben B. Establishing a Maori case management clinic. N Z Med J. 2003:116(1169):U328.

116. Knishkowy B, Schein M, Kiderman A, Velber A, Edman R, Yaphe J. Preventive adolescent health care in family practice: a program summary. ScientificWorldJournal. 2006;6:619-27.

117. Levin-Zamir D, Keret S, Yaakovson O, Lev B, Kay C, Verber G, et al. Refuah Shlema: a cross-cultural programme for promoting communication and health among Ethiopian immigrants in the primary health care setting in Israel: evidence and lessons learned from over a decade of implementation. Glob Health Promot. 2011:18(1):51-4.

118. Landi F, Onder G, Russo A, Tabaccanti S, Rollo R, Federici S, et al. A new model of integrated home care for the elderly: impact on hospital use. J Clin Epidemiol. 2001;54(9):968-70.

119. Pelcastre-Villafuerte B, Ruiz M, Meneses S, Amaya C, Márquez M, Taboada A, et al. Community-based health care for indigenous women in Mexico: a qualitative evaluation. Int J Equity Health. 2014;13(2):1-9.

120. Große J, Daufratshofer C, Igel U, Grande G. Community-based health promotion for socially disadvantaged mothers as health managers of their families: strategies for accessing the target group and their effectiveness. J Public Health. 2012;20(2):193-202

121. Alberta Health Services. Community Paramedics. 2017. http:// albertahealthservices.ca/info/Page12557.aspx.

122. Arora S, Thornton K, Murata G, Deming P, Kalishman S, Dion D, et al. Outcomes of treatment for hepatitis $C$ virus infection by primary care providers. N Engl J Med. 2011:364(23):2199-207.

123. Department of Health \& Human Services. Police, Ambulance and Clinical Early Response (PACER) evaluation report. Victoria State Government; 2012.

124. Huppert D, Griffiths M. Police mental health partnership project: police ambulance crisis emergency response (PACER) model development. Australas Psychiatry. 2015;23(5):520-3.

125. Fiore F. La clinique de transition: un pas vers un médecin de famille. Le Médecin du Québec. 2013;48(6):21-5.

126. Healthy Families BC. Nurse-family partnership. 2016. https://www. healthyfamiliesbc.ca/nurse-family-partnership.

127. Druss BG, Rohrbaugh RM, Levinson CM, Rosenheck RA. Integrated medical care for patients with serious psychiatric illness: a randomized trial. Arch Gen Psychiatry. 2001;58(9):861-8.

128. JPS Health Network. Behavioral Medicine. 2019. https://www.jpshealthnet org/academics_research/residency_programs/family_medicine/unique_ aspects of the program.

129. Khan G. Written Medicine. 2017. https://www.writtenmedicine.com/.

130. Northside Clinic. Northside Clinic. 2016. http://northsideclinic.net.au/.

131. Pariser P, Khakoo A, Pham T. Urban Telemedicine IMPACT Plus. 2015. https://www.afhto.ca/wp-content/uploads/F2-telemedicine-impact-plus.pdf.

132. SABSA. Super-infiermière, Clinique, Coopérative de solidarité SABSA. 2018. https://www.sabsa.ca.

133. Safetynet. Services. 2017. https://www.primarycaresafetynet.ie/services 
134. The Alex. Mobile Health at The Alex: Compassionate Care on Wheels. 2018. https://www.thealex.ca/mobile_impact/.

135. Vancouver Coastal Health. Youth Health. 2014. http://www.vch.ca/publichealth/children-youth-schools/youth-health.

136. Youth Projects. The living room. 2017. https://www.youthprojects.org.au/ the-living-room.

137. Hirmas Adauy M, Poffald Angulo L, Jasmen Sepulveda AM, Aguilera Sanhueza X, Delgado Becerra I, Vega MJ. Health care access barriers and facilitators: a qualitative systematic review. Rev Panam Salud Publica. 2013; 33(3):223-9.

138. Johannes B, Graaf D, Blatt B, George D, Gonzalo JD. A multi-site exploration of barriers faced by vulnerable patient populations: a qualitative analysis exploring the needs of patients for targeted interventions in new models of care delivery. Prim Health Care Res Dev. 2019;20(e6):1-11.

139. Powell RE, Doty A, Casten RJ, Rovner BW, Rising KL. A qualitative analysis of interprofessional healthcare team members' perceptions of patient barriers to healthcare engagement. BMC Health Serv Res. 2016;16:493.

140. Blendon RJ, Schoen C, DesRoches C, Osborn R, Zapert K. Common concerns amid diverse systems: health care experiences in five countries. Health Aff. 2003;22(3):106-21.

141. Corscadden L, Levesque JF, Lewis V, Breton M, Sutherland K, Weenink JW, et al. Barriers to accessing primary health care: comparing Australian experiences internationally. Aust J Prim Health. 2017;23(3):223-8.

142. Corscadden L, Levesque JF, Lewis V, Strumpf E, Breton M, Russell G. Factors associated with multiple barriers to access to primary care: an international analysis. Int J Equity Health. 2018;17(1):28.

143. Davis K, Ballreich J. Equitable access to care--how the United States ranks internationally. New Engl J Med. 2014;371(17):1567-70.

144. Ekman B. Community-based health insurance in low-income countries: a systematic review of the evidence. Health Policy Plan. 2004;19(5):249-70.

145. Hall CS, Fottrell E, Wilkinson S, Byass P. Assessing the impact of mHealth interventions in low- and middle-income countries - what has been shown to work? Glob Health Action. 2014:7:25606.

146. Asante A, Price J, Hayen A, Jan S, Wiseman V. Equity in health care financing in low- and middle-income countries: a systematic review of evidence from studies using benefit and financing incidence analyses. PLoS One. 2016; 11(4):e0152866.

147. Devarakonda S. Hub and spoke model: making rural healthcare in India affordable, available and accessible. Rural Remote Health. 2016;16(1):3476.

148. Kapoor A, Goyal S. Inclusive healthcare at base of the pyramid (BoP) in India. Int J Trade and Global Markets. 2013;6(1):22-39.

\section{Publisher's Note}

Springer Nature remains neutral with regard to jurisdictional claims in published maps and institutional affiliations.

Ready to submit your research? Choose BMC and benefit from:

- fast, convenient online submission

- thorough peer review by experienced researchers in your field

- rapid publication on acceptance

- support for research data, including large and complex data types

- gold Open Access which fosters wider collaboration and increased citations

- maximum visibility for your research: over $100 \mathrm{M}$ website views per year

At $\mathrm{BMC}$, research is always in progress.

Learn more biomedcentral.com/submissions 